\title{
Access to and quality use of non- communicable diseases medicines in Nepal
}

\author{
Bhuvan K.C. , Susan Heydon and Pauline Norris
}

\begin{abstract}
Noncommunicable diseases are a major healthcare problem in Nepal and their burden is increasingevery year. Noncommunicable diseases (NCDs) bring additional challenges to the Nepalese healthcaresystem which is already experiencing infrastructure shortages, poor service delivery, inadequate essential medicines coverage and shortages of healthcare workers. The Nepal government provides a limited number of free essential medicines through the free essential healthcare services program. This consists of a basic healthcare package provided through primary healthcare $(\mathrm{PHC})$ facilities and district hospitals. Though around 40 essential medicines are provided without charge, studies have reported problems with access especially in all rural areas. There is a need to improve access to, coverage and quality use of medicines. The government has decided to provide some free medicines for NCDs alongside free essential medicines to be distributed via current healthcare structures. Though well intended, this decision will put extra strain on the essential medicines program. It should be supplemented by a comprehensive NCDs policy that takes account of the issues of sustainability and quality use of medicines. Complex cases of NCDs will be managed by tertiary hospitals but most of the cases of NCDs especially for rural people and the poor will end up in secondary level public hospitals (district and zonal hospitals). Therefore, the government needs to strengthen these public hospitals. Meanwhile, given the severity of the NCDs problem in Nepal, the Ministry of Health and Population (MoHP) should liaise with nongovernmental and missionary hospitals especially in rural areas to run NCDs management services. The Ministry should encourage these hospitals to run hospital pharmacies to improve people's access to and quality use of NCDs medicines. At the primary healthcare level, the Ministry could run NCDs prevention and control programs but existing PHC workers need training to perform proper dispensing of NCDs medicines. PHC facilities need a medical record system so that they can address the needs of NCDs patients requiring long term medication supply via a proximate PHC facility.
\end{abstract}

\section{Background}

\section{The public healthcare system in Nepal}

Access to essential medicines for non-communicable diseases (NCDs) is a concern for Nepal as the incidence of NCDs in Nepal is increasing. The Nepal Government has approved the Ministry of Health and Population's (MoHP) decision to increase the number of free essential medicines from 40 to 70 by including medicines for NCDs, without developing comprehensive policy for NCDs [1]. This commentary analyses the impact of the decision on the quality use of medicines in Nepal and explores alternative mechanisms for NCDs medicines distribution.

Nepal is a low-income country in South Asia located between China and India. It has a population of 28.1

\footnotetext{
* Correspondence: bhuvan.kc@otago.ac.nz

School of Pharmacy University of Otago, 18 Frederick Street, Dunedin 9054, New Zealand
}

million, [2] of whom $44.2 \%$ are living below the poverty line as determined by the Multidimensional Poverty Index [3]. Health service delivery in Nepal lacks quality and universal coverage. Public health services are delivered via tertiary hospitals, regional and zonal hospitals in urban areas and via district hospitals, primary healthcare centers, health posts and sub-health posts in rural areas [4]. The Nepal Government initiated the free essential healthcare services (EHCS) program in 2007 which has now been scaled up to district hospital level [5]. The free EHCS program includes free primary healthcare (PHC) services, basic secondary care services and a limited number of free essential medicines [5]. People have to pay for all other health services in both the public and private sectors, and a significant proportion of healthcare financing consists of out-of-pocket expenditure (for example for medicines, doctors' visits, lab tests, transportation and hospital stays) [6]. While policy
C Biomed Central

(c) 2015 K.C. et al. Open Access This article is distributed under the terms of the Creative Commons Attribution 4.0 International License (http://creativecommons.org/licenses/by/4.0/), which permits unrestricted use, distribution, and reproduction in any medium, provided you give appropriate credit to the original author(s) and the source, provide a link to the Creative Commons license, and indicate if changes were made. The Creative Commons Public Domain Dedication waiver (http://creativecommons.org/publicdomain/zero/1.0/) applies to the data made available in this article, unless otherwise stated. 
initiatives towards universal health coverage and health sector reforms have been taken in order to improve health system efficiency, equity and accessibility of healthcare for underprivileged groups, [7] initiatives to improve the quality of healthcare services to retain patients at public health facilities are still lacking.

\section{The state of the free essential medicines program}

After the initiation of the free essential healthcare services program in 2007, the government has gradually increased its coverage so as to provide free basic healthcare and a limited number of essential medicines [8]. Providing free essential medicines is the first step, but there is much to do to improve coverage and quality use of essential medicines. Ensuring quality use of medicine in the Nepalese context requires: updating standard treatment guidelines, establishing pharmacy and therapeutic committees in hospitals to monitor quality use of medicines, conducting rational drug use training, updating essential medicines lists and strengthening health logistics provisions especially in PHC facilities $[9,10]$. This needs more resources and time. As of 2014, under the free EHCS program a limited number of medicines (25 at sub-health post and health posts, 35 at primary health care centers and 40 at district hospitals) are provided through primary healthcare facilities and district hospitals [7]. However, the actual need for medicines is much higher. A study report submitted to the National Planning Commission in 2012 showed that health service users $(N=100)$ reported year round availability of essential medicines to be $16.6 \%$ in health facilities from the Mountains, $57.1 \%$ in the Hills and $52.2 \%$ in the Terai (plains in the southern part of Nepal which borders with India and where more than $50 \%$ of the population lives) [11]. Year round availability of essential medicines was reported by only $25 \%$ of users in district hospitals, $40 \%$ in primary health care centers and $36.6 \%$ in health posts [11]. A review of the free essential healthcare services program reported that both the type and quantities of free essential medicines were insufficient for PHC facilities and district hospitals, expired medicines were present in health facilities and human resources were inadequate [12]. Thus, there is a need to improve logistics, human resource capabilities and coverage of the essential medicines program so as to improve access to and quality use of medicines to achieve the goals of the free essential healthcare services program.

\section{Non-communicable diseases burden in Nepal and quality use of medicine}

As stated in the Department of Health Services (DoHS) annual report 2013-14, $86 \%$ of new in-patient visits $(N=287,616)$ were the result of NCDs [13]. Two NCDs (other chronic obstructive pulmonary disease and essential (primary) hypertension) were among the top ten causes of in-patient mortality in public hospitals during 2013-14 [13]. The majority of NCDs in Nepal are cardiovascular diseases, injuries and neuropsychiatric conditions, cancers, chronic respiratory diseases and diabetes [13]. The population aged 65 years and older is projected to rise from $4.2 \%$ in 2000 to $5.8 \%$ in 2025 and therefore, the burden of NCDs is going to increase [14]. The government has developed a multi-sectoral action plan on the prevention and control of NCDs which aims to reduce preventable morbidity, avoidable disability and premature mortality due to NCDs [15]. Consequently, the government announced a plan for including NCDs medicines in the free essential medicines program in its budget for the fiscal year 2011-12 [16]. These medicines would be distributed through the present healthcare structure including PHC facilities [16]. Government initiatives for distributing NCDs medicines could be an opportunity to integrate NCDs medicines with the existing free essential medicines program and improve people's access to and quality use of medicines.

NCDs treatment requires long-term care enabled via a reliable healthcare facility and medicines supply system [17]. Experiences from Uganda and Rwanda show that chronic shortage of health workers, lack of access to basic health supplies and limited or unreliable financial resources were systemic challenges [18]. These are similar to Nepal in many ways. The NCDs prevention and control plan of Nepal included health system strengthening, especially $\mathrm{PHC}$, which includes preparing a package of essential medicines for NCDs, improving the competency of PHC workers to handle NCDs management and the promulgation of a three tier system viz. first tier- PHC level, middle tier- zonal and district hospital level, third tier-speciality centres [15]. Therefore, the government should develop a comprehensive NCDs treatment policy with appropriate treatment guidelines for various NCDs and clear demarcation of roles of each level of health facilities in NCDs management.

Zonal and district hospitals are proposed as second line facilities for the treatment and management of NCDs in Nepal [15]. However, many public hospitals in Nepal especially in far-western, mid-western region and the Terai region are in poor condition [19]. These hospitals lack human resources (specialist doctors and paramedics), appropriate infrastructure and the financial resources required to perform NCDs management services [19] [20]. Most need upgrading, which is beyond the MoHP's capacity. Nevertheless, some combined initiatives of the government and aid agencies to provide environmental support for rural staff have increased patient utilization in Bajhang, Gulmi and Dolakha districts [21]. Likewise, nongovernmental organization (NGOs) 
and mission hospitals have provided much needed secondary level care in Dadeldhura, Okhaldhunga, Lamjung, Palpa, Kavre and Accham districts [22]. Nepal today has enough pharmacists to cover all district hospitals to promote quality use of medicines [23, 24]. The MoHP thus needs to liaise with NGOs and mission hospitals to run NCDs treatment program in districts with limited public hospital serves and encourage district hospital management committees' to develop hospital pharmacy so as to improve people's access to and quality use of NCDs medicines.

Since distributing NCDs medicines through the free essential medicines program involves PHC facilities, they need to be strengthened. Nepal has a successful track record of employing primary healthcare workers such as auxiliary health workers, village health workers and auxiliary nurse midwives in immunization program, mass medication of albendazole and diethylcarbazide, distribution of anti-TB medicines, reproductive and maternal health programs $[25,26]$. A systematic review from low-and-middle income countries also supports their use as an effective and affordable approach for making healthcare accessible for NCDs but such step needs to be accompanied by health system restructuring [27]. Community health workers were also involved in the management of non-communicable health problem at community level in countries like Pakistan, India and Bangladesh [28]. The government needs to introduce training programs for these PHC workers so that they can distribute NCDs medicines without compromising quality use and establish a networking system between PHC facilities and public hospitals so that NCDs patients can be tracked and enrolled in NCDs treatment programs.

The government has proposed to distribute NCDs medicines by including them in the free essential medicines list and delivering them via the same healthcare structures [1] which will increase the logistics burden of the program. Furthermore, need for NCDs medicines will depend on the local prevalence data. Therefore, the government has to improve the health logistics infrastructure at regional and district level so that they can deliver needed NCDs medicines. Furthermore, upgrading medicines stores at district health offices and PHC facilities is required so that medicines can be stored properly and quality of medicines maintained.

\section{Conclusion}

The distribution of NCDs medicines is a major and long term issue for which the government needs to ensure sustainability and quality use of medicines. The government needs to work towards prevention, control and management of NCDs. Complicated cases of NCDs will be managed at tertiary level but the majority of the NCDs patients will be treated in public hospitals at district and zonal level. The government needs to gradually strengthen these hospitals with appropriate human resources and infrastructure. However, given the seriousness of NCDs problem utilizing nongovernmental and mission hospitals at district level and encouraging them to run hospital pharmacies might improve access to and quality use of NCDs medicines. At PHC level, the focus should be on running comprehensive NCDs prevention and control programs and training existing PHC workers in rational dispensing of NCDs medicines. Such activity requires a comprehensive approach, sustainable financing and integration with a multi-donor program like Nepal Health Sector Support Programme.

\section{Abbreviations}

DoHS: Department of Health Services; EHCS: Essential Health Care Services; GoN: Government of Nepal; MoHP: Ministry of Health and Population, Nepal; NCDs: Non-communicable diseases; PHC: Primary Health Care;

TB: Tuberculosis.

Received: 12 January 2015 Accepted: 14 August 2015

Published online: 31 August 2015

\section{References}

1. Ministry of Health and Population, Nepal. Increasing the number of free essential medicines to 70. Ministry of Health and Population (GoN), Kathmandu; 2014. http://www.mohp.gov.np/images/pdf/notice-board/ Drug_List_for_Free_Health.pdf.

2. World Bank Group. Nepal. 2014. http://data.worldbank.org/country/nepal. Accessed 7 July 2015.

3. Oxford Poverty and Human Development Initiatives. Nepal country briefing. Wellington Square, Oxford: Multidimentional Poverty Index Data Bank, Oxford Poverty and Human Development Initiatives, University of Oxford; 2015.

4. Rai SK, Rai G, Hirai K, Abe A, Ohno Y. The health system in Nepal- an introduction. Environ Health Prev Med. 2001;6:1-8.

5. Adhikari Shivraj. An evaluation of Nepal's free health care scheme: evidence from a quasi-experimental design. In: Social Science Research Network. 2013. http://papers.ssrn.com/sol3/papers.cfm?abstract_id=2289344. Accessed 16 July 2014

6. Magar A. Envisaging beyond community-based health insurance in Nepal. J Nepal Health Res Council. 2014;11:I-II.

7. Schurmann M. Developing a list of tracer medicines for the Nepal health sector support programme-2. Kathmandu: Nepal Health Sector Support Programme, Ministry of Health and Population (GoN); 2012.

8. Health Sector Reform Support Programme. Free health care in Nepal: findings of the rapid assessment. Kathmandu: Health Sector Support Programme, Department of Health Services, (GoN), Deutsche Gesellschaft für Technische Zusammenarbeit; 2009

9. International Network for Rational Use of Drugs N. Inrug-Nepal collection. http://www.inrud-nepal.org.np/background.php. Accessed 2 July 2015.

10. Laing $R$, Hogerzeil $H$, Ross-Degnan D. Ten recommendations to improve use of medicines in developing countries. Health Policy Plann. 2001;16(1):13-20.

11. Development Resource Centre. Essential drug procurement and distribution program under free health services. Kathmandu: National Planning Commission (GoN); 2012

12. Prasai DP. A review of studies on Nepal's national free health care programme. Kathmandu: Primary Health Care Revitalization Division, Department of Health Services, Ministry of Health and Population (GoN); 2013.

13. Department of Health Services. Annual report of the Department of Health Services 2070/71 (2013/2014). Kathmandu: Department of Health Services, Ministry of Health and Population (GoN); 2014 
14. World Bank Group. Non-communicable diseases (NCDs)- Nepal's next major challenge. World Bank, Washington, DC; 2011.

http://siteresources.worldbank.org/SOUTHASIAEXT/Resources/2235461296680097256/7707437-1296680114157/NCD_NP_Policy_Feb_2011.pdf. Accessed 10 July 2014

15. Government of Nepal. Multisectoral action plan for the prevention and control of non communicable diseases (2014-2020). Kathmandu: Ministry of Health and Population (MoHP-Nepal), World Health Organization Country Office Nepal; 2013.

16. Ministry of Finance. Budget speech of fiscal year, 2011-2012. Kathmandu: Ministry of Finance (GoN); 2011.

17. NCD Alliance. NCD alliance briefing paper: access to essential medicines and technologies for NCDs. NCD Alliance; 2011

18. Management Sciences for Health, Livestrong Foundation. A health systems approach to non-communicable diseases in Uganda and Rwanda. Massachusetts: Management Science for Health, LIVESTRONG Foundation; 2014.

19. Andrew J. Nyaya health. 2011. http://blog.nyayahealth.org/2011/03/05/ ncd_nepal_globally/. Accessed 15 July 2014.

20. Ministry of Health and Population, Nepal Health Sector Support Program. Human resources for health strategic plan 2011-2015. Kathmandu: Ministry of Health and Population, Nepal, Nepal Health Sector Support Program; 2012.

21. Nick Simons Institute. Mid-term assessment of the rural staff support program (RSSP). Kathmandu: Nick Simons Institute; 2010.

22. Marasini BR. Health and hospital development in Nepal: past and present. J Nep Med Assoc. 2003;42(149):306-11.

23. Nepal Pharmacy Council. Pharmacy assistants registered with Nepal Pharmacy Council. NPC Newsl. 2014;3:8-12.

24. KC B, Alrasheedy AA, Ibrahim MIM. Do community pharmacists in Nepal have a role in adverse drug reaction reporting systems? Australas Med J. 2013;6(2):100.

25. Nepal Health Scetor Support Program. Nepal Health Sector Programme-2 implementation plan. Kathmandu: Nepal Health Sector Support Program; 2010.

26. Pokharel RK, Maharjan MR, Mathema P, Harvey PWJ. Success in delivering interventions to reduce maternal anemia in Nepal: a case study of the intensification of maternal and neonatal micronutrient program. Kathmandu: U.S. Agency for International Development; 2011.

27. Joshi R, Alim M, Kengne AP, Jan S, Maulik PK, Peiris D, et al. Task shifting for non-communicable disease management in low and middle income countries-a systematic review. PLoS One. 2014;9(8):103754.

28. Bhutta ZA, Lassi ZS, Pariyo G, Huicho L. Global experience of community health workers for delivery of health related millennium development goals: a systematic review, country case studies, and recommendations for integration into national health systems. Global Health Workforce Alliance: World Health Organization; 2010. 